\title{
Study on the 4P method based on the study of leading enterprise management practice in China
}

\author{
XIONG Yan \\ Nanchang Institute of Science and Technology, Nanchang 330108,China
}

Keywords: management practice research; methodology; 4P; practice; leading enterprises.

\begin{abstract}
Chinese based on context, Constructivism from interaction between knowledge and practical knowledge, On the basis of long-term leading enterprise management practice concerned results leading technology of China ,From the practice theory of scarcity, fatigue, local characteristics, the subject of great value of fixed value frame leading enterprise management practice research, The construction and demonstration of embedded Practice Center"4P practice problem proposition / model theory" theory, According to local management practices as critical research methods in China.
\end{abstract}

\section{Introduction}

Since the face issues of management practice Chinese rise in domestic and overseas, More and more scholars and practitioners involved. Over the past 5 years, Many scholars are moving towards the method to construct Chinese local management knowledge, To discuss the China theory development management. Although many scholars have proposed high perspicacity, But the researchers especially in the face of complex and diverse Chinese management practice, In order to develop both theory and practice of "knowledge management, There is a long way to go, There are many problems to be faced in suspense. Based on this,In this study, grounded and management practice immersed in Chinese situation, To find and solve important problems in management practice, Study on management practice to find out the essential attributes of the China management practice, Study on the 4P method based on the study of leading enterprise management practice in China

\section{Analysis of research on local path Chinese management literature}

How to carry out the research on local management Chinese, Especially the study of face management practice; How to choose the way of scientific value and method to develop, The local situation, China theory of discourse identity? This is a problem many scholars thought and exploration in recent years. Back on the topic of literature can be seen, The researchers in the mastery of the basic methodology of social science, And grasp the overall situation of management under the premise of China, Mainly from combining destruction, context and culture, 3 from the perspective of scientific methodology paradigm to explore the issue of local management of the road. 
From the combining destruction. According to the empirical study on the management of China abuse and deification, The results of value and influence is very limited, And hindered the popularity of multi paradigm in the study of management in Chinese and a. Now, many scholars such as Han Wei, etc., The main research from philosophy, theory, method, practice, The evaluation results and other aspects of the criticism; According to the management research and management researchers widespread research status from practice, Almost all committed to "China management theory" of the scholars in the reflection, Especially in the 39 scholars signed article as a representative.

In the process of criticism and reflection, many scholars put forward new ideas, the local management of the road, Exploration of these roads also covers the basic situation and the culture mentioned above, The scientific method (Theory) on the two / integration perspective. For example: row forward the research management Chinese, should be rooted in the China. Cultural tradition, social situation, based on the experience of the organization, The new "induction" with "path of localization" support experience; Xie Peihong in the summary of the problems of domestic critical management studies, That Chinese based on traditional culture, Chinese situation of modern China management practice and based on the theory of Western management, These 3 paths are helpful to the development of local Chinese management; Lu force put forward the research and methods of normative theory rather than empirical methods to solve practical problems in the practice of local management China and contradiction.

From the perspective of context and culture. It is based on the change of existing management theory and knowledge based on context and culture Sensitivity),And the specific situation and cultural management practices may produce unique management knowledge (situational creativity), How to explore the variables of context and culture in local management research, Or directly after the main guide to discover the characteristics of China's local management,

From this point of view to explore China's local management research path, In the current domestic research in this theme occupies a dominant position. Through the literature review, The main ways to explore the path of China's indigenous management research, And to ensure that researchers have in-depth analysis and insights. However, when we criticize the positivist research. The western management theory of knowledge, from the practice of intellectualism, Current situation of utilitarianism; When we put forward the opposite or more rational research methods and methodology, We are still concerned about the "management practices":The scholars put forward the methodology can really effectively embedded in the rich and complex management practice world. An important reason for this judgment is: Most of the research on the practice path, The "practitioner" of management -- whether it is the influence of the object of practice", As the main body of research", Little is mentioned in these literature, and they are our study, Especially in the practice of management, it is almost impossible to "role" The introduction of entrepreneurs to participate in the forum of China management, practice and forum held every year, Practice and model of dialogue, It is an effort to explore the research activity of entrepreneurs into the research topic of scholars. 
Further more, Sociologist Mills pointed out the necessity of the progress of methodology: Only when the methodology is discussed as a direct reference to practical research, It should be given serious attention. At present, although more and more scholars agree and advocate the study of management practice (or practice oriented management research), That is to deepen the management practice in China, and find out the major problems in practice, Research on the essential attributes of Chinese management practice; However, only a few studies, Hu Tao discusses how to "manage practice", To find the "management knowledge" which belongs to the management practice of China and the local characteristics of Chinese management, The use of its methodology to achieve the effectiveness of management practice is more scarce.

\section{The interaction of knowledge and practice in management practice research:}

Social Constructivism Perspective. Exploring the methodology of management practice research, First of all, from the epistemological and practical aspects, Solve the relationship between knowledge and practice, That is, what kind of standpoint and viewpoint the researchers use to examine the practice of management knowledge and the production of management knowledge. This is the first problem that researchers must face in the face of management practice, It is also the basic question of whether the management practice research can produce and whether it is scientific and effective.

The theory of social construction in the sociology of science is the understanding of the relationship between knowledge and practice in management practice, It provides the basis of philosophy of Science. The most fundamental and important contribution of social constructivism to science lies in its knowledge of what it is and why, A firm empirical study. Social constructivism theory, Scientific achievements (including experience),Its characteristic is the product of the construction process, Knowledge in some fields is the product of social practice and social system constructed by human beings. Is shaped by the social context, Is people in practice. The mouth that will be constructed. Therefore, the view of scientific knowledge based on constructivism: Scientific knowledge and humanistic knowledge have essentially the same nature, It is the product of human practice, Have a social and cultural formation of the heart.

\section{Research on 4P methodology in management practice research}

After the management researchers understand the relationship between professional knowledge and management practice, For all interested in the development of local management knowledge from business management practice, The most concern is: how should from the practice of manpower, To explore the knowledge of management practice research, What is the logic of management practice research? This is the scientific research of local management practice, Basic questions must be answered. Refer to the achievements of many scholars on the research path of management practice, Based on the experience and experience of the case study of China's local enterprises based on the leading channel, Present paper, A study on the management practice of China's leading enterprises (hereinafter referred 
to as "local management practice research"),It should be through practice as a starting point and 4P.(practice; problem; proposition; point of view)Research methodology to find and build the theoretical knowledge of local management. The following several aspects of the framework of the mechanism and Practice.

The research is suitable for the research of practice perception. The study of local management practice is based on the problem oriented personnel, Is to start with the literature as a good, or a good sense of practice, This may not make a simple judgment. However, the practice of methodological master Bourdieu pointed out, The most formidable obstacle of practical science is that "the joint relationship between scholars and subjects makes it possible for them to get used to (Science),Publicize the superiority of the acquired knowledge. In the research of management practice, The researchers who have been trained in the academic field structure for a long time, In the field of practice, it is easy to bring forward the research ideas and presupposition, So that the researchers can discover and summarize the problems or manage the knowledge from the practical facts. Thus it seems, The researchers who are engaged in the research of local management practice are more suitable for the "practical perception", Avoid any research assumptions and theories, and carry out the spirit of taking root.

To find and frame significant research questions from practice. Researchers rooted in management practice can not stay in the management of learning state, And interest in the operation of the business management, The understanding of the important practical problems is the most important step in the research of management practice, It is also the fundamental purpose of managers' practical perception. From the development history of management thought, the important theories from management practice, Such as: Taylor's scientific management, the functional management of Fayol, Drucker's goal management, model of corporate culture, such as 7S,It does not begin with the understanding of the major practical issues of that time and to put forward theoretical thinking and Solutions. Therefore, in the practice of management and the perception of the facts, The problem of "framing the problem" should be placed in the first place, which is a major practical problem that affects the core competence of most Chinese enterprises, Thesis (practice scarcity), The existing management theory is not effectively explain and promote the solution of this problem (theory of fatigue), to explore the theory and idea of China scheme with the situational and cultural factors could provide more "original" (local features),Can the study of this problem provide a model or theory for "management theory of China "Fulcrum (subject value) to investigate and judge. A research or research thesis can recognize these 4 questions, Its theoretical innovation, practical innovation and China's local characteristics are bound to appear.

To refine the theme or proposition from focusing on practice and framing. Frame problem in practice, In fact is to determine the direction of management practice research, In most cases we may have more than one problem, And whether there is a logical relationship between these questions? How does the framing problem exist in the existing literature, Where are the gaps? What are the management concepts contained in the frame problem, What is the definition of the problem and whether the problem in the follow-up study needs to be connected with the management practice?, How to butt these are placed in front of the researchers must 
seriously consider and plan the thinking problem box. The core of these thinking problems, in fact, is the focus of practice, refining proposition”, Focus on Problems and practices, Find a research or logical framework, it can pierce the main practical problems, Practice and research concepts, The study of management practice has a more clear "problem oriented and problem oriented", And refine the problem into a logical relationship between concepts or variables, A propositional hypothesis or model of fuzziness, This is different from the hypothesis that empirical research requires rigorous and theoretical reasoning. Therefore, the frame of the problem will be refined into a model, That is to say, the researchers use the academic imagination to "guess" the questions of the frame, This is very necessary and useful, Scientific conjecture is a necessary methodology in scientific activities, especially in innovation.

\section{Conclusion}

American management scholar VAN DE VENH put into action management practices, The study of the involvement of the management practitioners is called "the input type of academic research”, He believes that this kind of research can not only improve the possibility of knowledge creation, It is also possible to bring about the innovation of research methods for indigenous research. It also encourages us to start from the perspective of constructivism, Based on the long-term observation and practice of leading enterprises in china, Trying to refine the 4P research methodology is a driving force for the management of local practice. From the point of the full text design and discussion, This paper only gives a basic framework of the methodology of management practice research, However, based on the 4P methodology, the study on how to deal with the cultural, situational factors, make the study show the national character, the adaptability; What is the role and structure of the practitioner and his empiricism in 4P methodology; How to embed multiple methods in practice research in 4P methodology; Does the research methodology of local management practices allow practical research to produce local management knowledge? These problems will be revealed in the framework of basic methodology for management practice research, Based on the research and practice of the author's management practice, Launched a series of research and exploration.

\section{References}

[1] Zhao L L, Shi M L, Sun Q Y. The Research and Practice of ERP Implementation Methodology Based on Hall Three Dimension Structure Model[J]. Applied Mechanics \& Materials, 2014, 543-547:4604-4608.

[2] Brown R, Brignall S. Reflections on the use of a dual-methodology research design to evaluate accounting and management practice in UK university central administrative services[J]. Management Accounting Research, 2007, 18(1):32-48.

[3] Zou P X W, Sunindijo R Y. 7. Research Methodology and Research-Practice Nexus[M]/Strategic Safety Management in Construction and Engineering. John Wiley \& Sons, Ltd, 2015:180-213.

[4] Li P P. Research Methodology in Strategy and Management Emerald Book Chapter: Toward Research-Practice Balancing in Management: The Yin-Yang 
Method for Open-Ended and Open-Minded Research Peter Ping Li[J]. 2012, 8(2012):91-141.

[5] Gavan R L. Enterprise Risk Management Practice[M]. Scholars' Press, 2012.

Tucker B P, Lowe A D. Practitioners are from Mars; academics are from Venus?: An investigation of the research-practice gap in management accounting[J]. Accounting, Auditing \& Accountability Journal, 2014, 27(3):394-425.

[6] Braguglia, Kay H.Jackson, Kanata A. Teaching Research Methodology Using a Project-Based Three Course Sequence Critical Reflections on Practice.[J]. American Journal of Business Education, 2012, 5(3):347-362.

[7] Borgström B, Dan F. Towards a methodology for studying supply chain practice[J]. International Journal of Physical Distribution \& Logistics Management, 2012, 42(8/9):843-862.

[8] Miller K D. The Problem of Method and the Practice of Management Research[J]. Research Methodology in Strategy \& Management, 2005, 2(2):143-177.

[9] He P. Causes and Countermeasures of the Gap between Management Research and Management Practice[J]. Management Review, 2011. 